\title{
THIRD TRIMESTER PRENATAL DIAGNOSIS OF MECONIUM PERITONITIS FOLLOWING ILEAL ATRESIA: CASE REPORT
}

\author{
MARCELLO VIGGIANO, BRUNA TAVARES, JOÃO LUCAS NETO
}

\begin{abstract}
Ileal atresia in association with meconium peritonitis is a rare condition for which the mechanism underlying the bowel perforation has not been fully recognized. We present a case of fetal meconium peritonitis with ileal atresia and a hyper-coiled umbilical cord. Clinically, the cause of obstruction and perforation is considered to be a consequence of congenital vascular anomalies.

The infant was born at 35 weeks of gestation and survived after postnatal multidisciplinary treatment. Our experience suggests that ultrasound recognition of this rare condition will enable early diagnosis and adequate surgical management for fetuses with meconium peritonitis following bowel obstruction.
\end{abstract}

KEYWORDS: MECONIUM PERITONITIS; ILEAL ATRESIA; PRENATAL DIAGNOSIS

\section{INTRODUCTION}

Meconium peritonitis (MP) is a local sterile chemical peritonitis that results from perforation of the bowel in the uterus 1. It has an estimated prevalence of 1 in 35,000 births. Possible causes and pathogenesis include mesenteric ischemia, volvulus, intestinal atresia, meconium plugs, internal hernia, Hirschsprung's disease, colon atresia and cystic fibrosis 1-5. All cases of MP have the same etiology; intrauterine bowel perforation and intraperitoneal inflammation by subsequent leakage of meconium. The differences between the types of diseases (generalized, cystic and fibroadhesive) depend on the time of perforation during pregnancy.

Lately, the survival rate for MP has increased as a result of advances in fetal diagnosis techniques and proper management, including postnatal surgical procedures and neonatal intensive care. 2,4,6,7

Here, we report a case of a routine third trimester ultrasound that was helpful in establishing a diagnosis of meconium peritonitis and determining a neonatal management plan.

\section{CASE REPORT}

A 24-year-old primigravid was referred to our hospital at $35+1$ weeks of gestation due to local fetal intestinal ex- pansion and mild polyhydramnios. On referral, a detailed ultrasonography showed an intra-abdominal cystic-type meconium peritonitis of $6.3 \times 4.8 \mathrm{~cm}$ associated with bilateral hydrocele, hypercoiled umbilical cord and an amniotic fluid index of $27.2 \mathrm{~cm}$ (Figures 1-4).

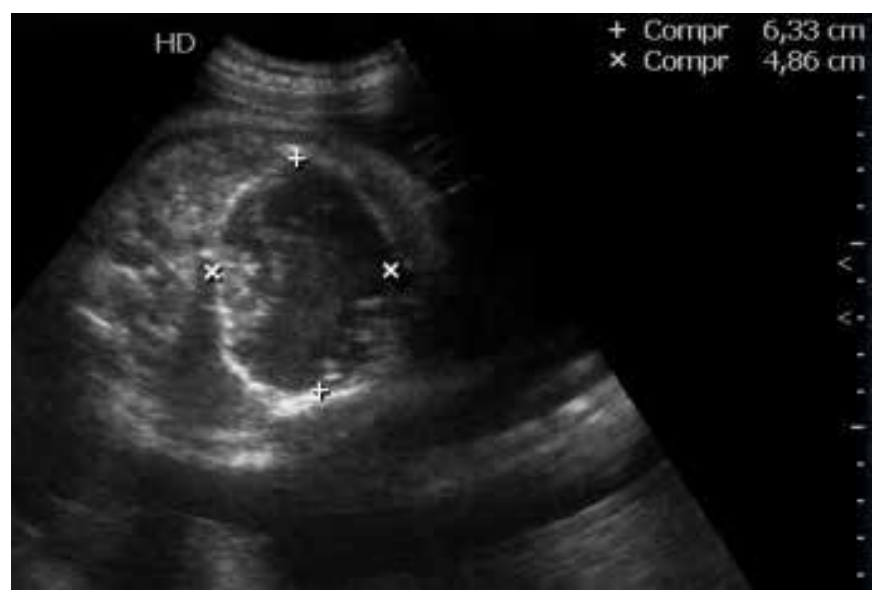

Figure 1. Large intra-abdominal cystic-type meconium peritonitis $(6.3$ $x 4.8 \mathrm{~cm}$ ).
1. Hospital Materno-Infantil, Universidade Federal de Goiás, Goiânia, Brasil

\section{MAILING ADDRESS}

DR. MARCELLO VIGGIANO

Rua 1028 n.70 apt. 902 Setor Pedro Ludovico

Goiânia-GO - CEP 74823-130

Email: marcelloviggiano@ig.com.br 


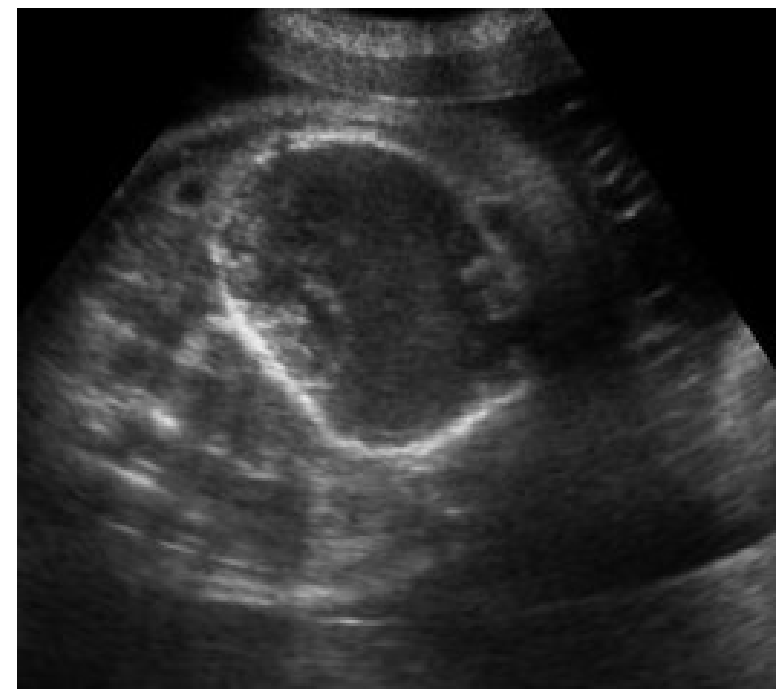

Figure 2. Intra-abdominal hyperechogenic areas representing peritoneal calcifications.

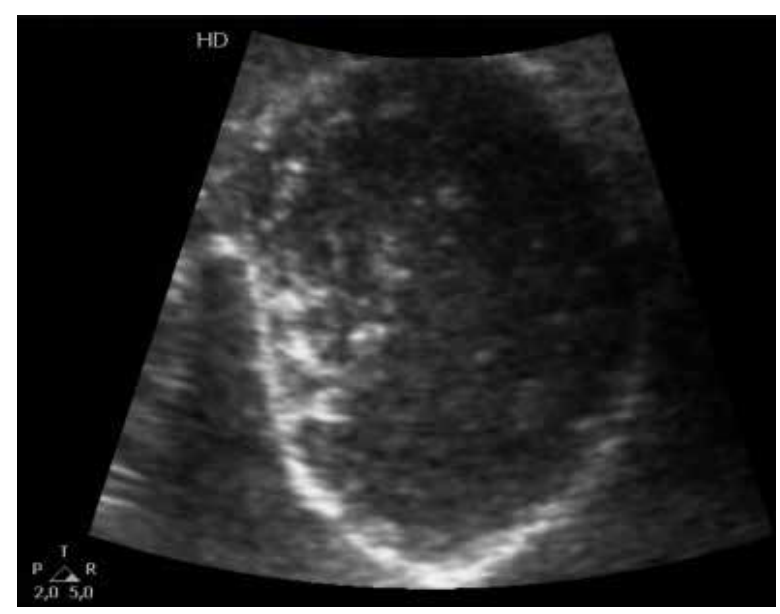

Figure 3. Peritoneal calcifications inside the cystic-type meconium peritonitis.

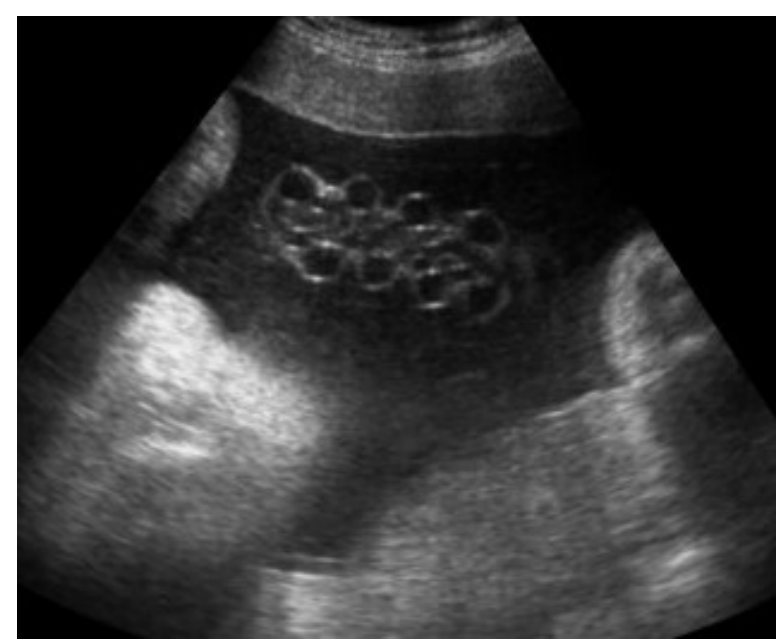

Figure 4. Hypercoiled umbilical cord.
A fetal anatomical survey excluded structural anomalies. Maternal immunoglobulin $M$ analysis excluded TORCH infections. The patient had no medical or family history of illness.

An acute worsening of intestinal obstruction was suspected on follow-up examination, with an increase in amniotic fluid to $31.5 \mathrm{~cm}$. Cesarean section was performed and a male baby was born weighing 2,531g with Apgar score of 8 and 9. At two days of life, exploratory laparotomy was performed for abdominal distention, which confirmed the suspicion of cystic-type meconium peritonitis. Due to the difficulty in delineating the viable bowel, a $15 \mathrm{~cm}$ terminal ileum resection was performed after the diagnosis of perforated ileum atresia with mucosal fistula formation (Figure 5).

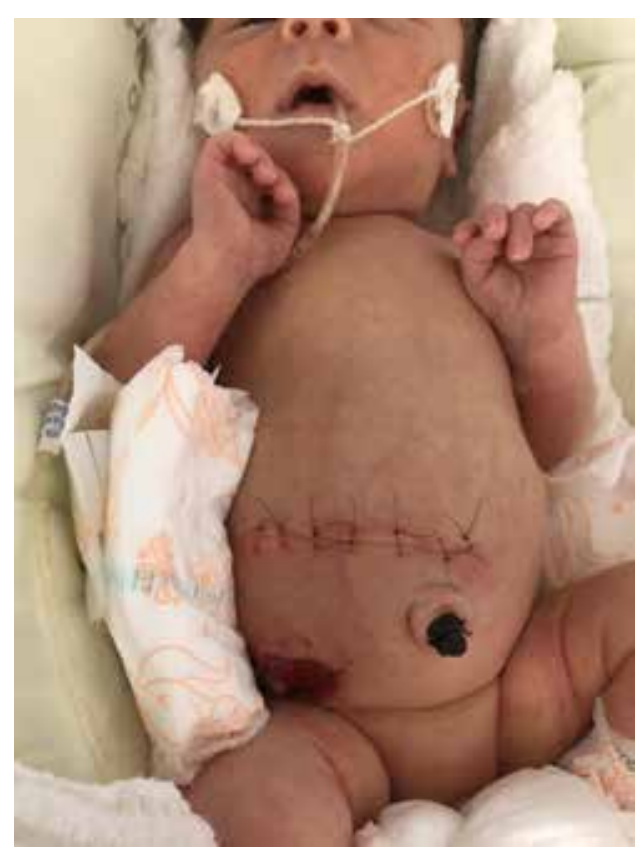

Figure 5.Terminal ileum resection with a mucous fistula creation.

In the last two months of follow-up, this child showed normal growth without any gastroenterological complications; and is awaiting the second stage approach to reconstruct bowel continuity.

\section{DISCUSSION}

Meconium is a complex mixture of bile salts, cell debris and proteins. Shedding of these constituents has been shown to activate immune cells, including macrophages 1,3 . Macrophages infiltrate the peritoneum and participate in a variety of cellular functions, including phagocytosis, release of chemical mediators, and antibody-dependent cell-mediated cytotoxicity. 8

Meconium peritonitis can have a wide variety of disease causes and clinical presentations. In this case report, the cause 
and pathogenesis of MP was intestinal atresia, which is consistent with the published literature, confirming the high rate of intestinal obstruction that affects these pregnancies. 2-4

Ultrasonographic diagnosis is based on the presence of intra-abdominal hyperechogenic areas that represent peritoneal calcifications and, additionally, dilated intestinal loops, ascites, and meconium pseudocyst. The incidence of chromosomal abnormalities and genetic syndromes is not higher; but there is an elevated risk of cystic fibrosis of up to $75 \% .4 .6$

Several studies have evaluated the accuracy of prenatal ultrasound testing to diagnose MP and predict patient outcomes. 2,6,8 The surgical strategy combined with decompression of the cyst drainage followed by temporary enterostomy soon after birth delays the reconstruction of intestinal continuity, and is recommended, by some reports, for the cystic type of MP, but the procedure after birth depends on the clinical presentation and general condition of the patient. 3.7

To improve the critical condition of patients, intrauterine surgical intervention, such as fetal paracentesis, can be beneficial, reducing intra-abdominal pressure and removing inflammatory residues and cytokines. 8-10

In conclusion, prenatal diagnosis is important for the first stage of perinatal MP therapy, and routine third-trimester ultrasound should be considered for some late-onset abnormalities. Timing of delivery and fetal intervention according to fetal conditions should be discussed with neonatologists and pediatric neonatal surgeons in perinatal and tertiary maternal care centers. Proper surgical procedures to reduce systemic and abdominal inflammation after birth can improve the outcome of severe cases of MP.

\section{REFERENCES}

1. Lorimer Jr WS, Ellis DG. Meconium peritonitis. Surgery 1966;60: 470-475.

2. Chan KL, Tang MH, Tse HY, Tang RY, Tam PK. Meconium peritonitis: prenatal diagnosis, postnatal management and outcome. Prenat. Diagn. 2005;25: 676-682.

3. Kamata S, Nose K, Ishikawa S, Usui N, Sawai T, Kitayama Y, et al. Meconium peritonitis in utero. Pediatr. Surg. Int. 2000;16: 377-379.

4. Shyu MK, Shih JC, Lee CN, Hwa HL, Chow SN, Hsieh FJ. Correlation of prenatal ultrasound and postnatal outcome in meconium peritonitis. Fetal Diagn. Ther. 2003;18: 255-261.

5. Kanamori Y, Terawaki K, Takayasu H, Sugiyama M, Komura M, Kodaka T, et al. Interleukin 6 and interleukin 8 play important roles in systemic inflammatory response syndrome of meconium peritonitis. Surg. Today 2012;42: 431-434.

6. Wang CN, Chang SD, Chao AS, Wang TH, Tseng LH, Chang YL. Meconium peritonitis in utero - the value of prenatal diagnosis in determining neonatal outcome. Taiwan J. Obstet. Gynecol. 2008;47: 391-396.

7. Nam SH, Kim SC, Kim DY, Kim AR, Kim KS, Pi SY, et al. Experience with meconium peritonitis. J. Pediatr. Surg. 2007;42: 1822-1825.

8. Topley N, Mackenzie RK, Williams JD. Macrophages and mesothelial cells in bacterial peritonitis. Immunobiology 1996;195: 563-573.

9. Osawa T, Soeda S, Watanabe T, Sato K, Sato A. Repeated paracentesis in a fetus with meconium peritonitis with massive ascites: a case report. Fetal Diagn. Ther. 2008;24: 99-102.

10. Uchida K, Koike Y, Matsushita K, Nagano Y, Hashimoto K, Otake K, et al. Meconium peritonitis: prenatal diagnosis of a rare entity and postnatal management. Intractable Rare Dis. Res. 2015;4(2): 93-97. 